\title{
COVID-19, Social Media, and the Role of the Public Physician
}

\author{
Joel M. Topf ${ }^{a}$ Paul N. Williams ${ }^{b}$ \\ aDepartment of Medicine, Oakland University William Beaumont School of Medicine, Rochester Michigan, \\ Rochester, MI, USA; 'bepartment of Medicine, Lewis Katz School of Medicine at Temple University Hospital, \\ Philadelphia, PA, USA
}

\section{Keywords}

Social media · Twitter - Youtube · COVID-19 - SarsCoV2 .

Public health $\cdot$ Infodemic ing misinformation was a core part of their mission. Public physicians on social media are a new occurrence and are an important part of fighting online misinformation.

(c) 2021 S. Karger AG, Basel

\section{Introduction}

The coronavirus pandemic of 2020 is the first global health crisis in the age of social media. During this pandemic, there have been countless examples of social media being used to both mitigate and, unfortunately, propagate harm. Infodemic is used to describe the "overabundance" of information in response to an epidemic and applies equally to factual information as well as misinformation [1]. The spread of this information can be compared to the pandemic itself, but the frictionless communication inherent in social media allows information to spread even faster than the virus [2].

Social media is equally efficient at spreading information as misinformation, and the nature of social media results in celebrities and influencers having outsized impact on what information is spread [3]. Widely known public figures making false and misleading claims, such as advocating for the use of unproven or potentially dan- karger@karger.com

www.karger.com/bpu

(c) 2021 S. Karger AG, Basel

Karger ${ }^{\prime}=$
Joel M. Topf

Oakland University William Beaumont School of Medicine

1800110 Mile Road, Suite 1

Rochester, MN 48066 (USA)

joel.topf@gmail.com 


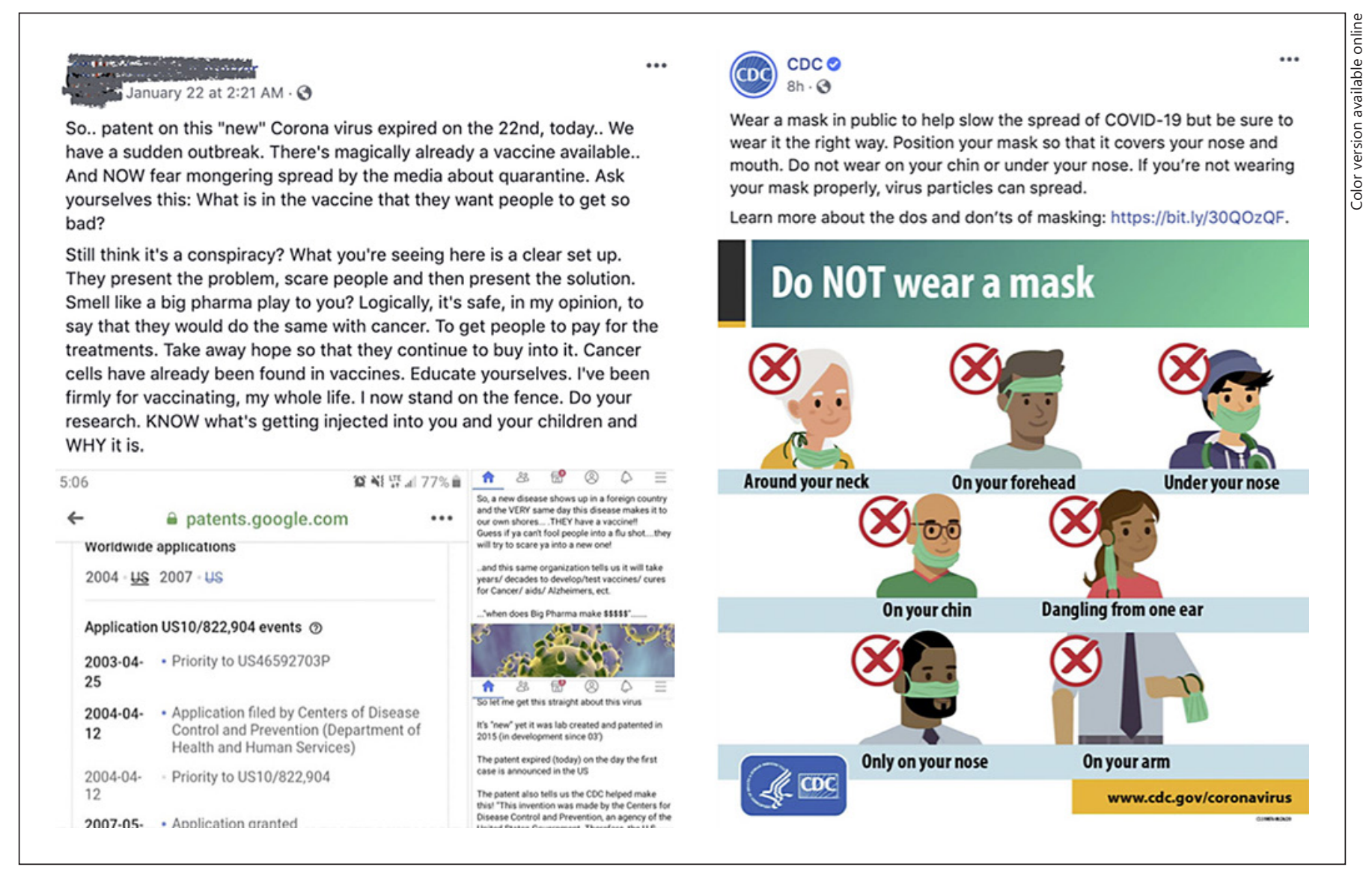

Fig. 1. The format of Facebook flattens contextual clues to the validity of a post so that posts by reputable sources like the CDC have a similar look to the ravings of an ill-informed commentor. CDC, Centers for Disease Control.

gerous therapies, can cause public harm and exacerbate the outbreak [1]. In January 2020, a Belgian physician, Kris Van Kerckhoven, told the newspaper Het Laatste Nieuws that $5 \mathrm{G}$ was life-threatening and linked to the coronavirus. The newspaper quickly issued a correction and deleted the article, but it was too late. Anti-5G groups began spreading the rumor. In early April, celebrities started inflating the rumor by posting it to Twitter and Instagram [4]. This resulted in spate of arson attacks on $5 \mathrm{G}$ cell towers across Europe [5].

Even when not overtly harmful, the sheer volume of dubious or not useful information poses the risk of drowning out more useful information. One study examined 117 videos (with nearly 1.2 billion total views at the time of publication) about coronavirus posted to TikTok, the popular video-based social media platform, and found that there was little to no useful information to be found [6]. A study of 113 YouTube videos about coronavirus categorized $60 \%$ of them as being useful, $9 \%$ as mislead- ing, and $21 \%$ neither useful nor misleading, while another found that over a quarter of YouTube videos about coronavirus contained misleading information $[7,8]$.

This propagation of misleading or nonfactual information on social media has the obvious potential for harm. Individuals who use social media as their primary source of information are more likely to have conspiracyrelated beliefs about coronavirus and less likely to engage in health-protective behaviors [9]. Social media, due to its algorithmic design has the capacity to create "filter bubbles," a monoculture where an individual's biases are reflected back to them by other like-minded people, potentially reinforcing untrue or dangerous beliefs [10]. Additionally, on platforms like Facebook and Twitter, fringe conspiracy beliefs take the same visual format as highvalue sources like the Centers for Disease Control and Prevention and The New York Times. Social media platforms remove contextual clues people normally use to assess information validity (see Fig. 1). 
Table 1. The public physicians we engaged in this article. Sources: Twitter.com, YouTube.com, Instagram.com, iTunes, and personal communication. Accessed 09/14/2020

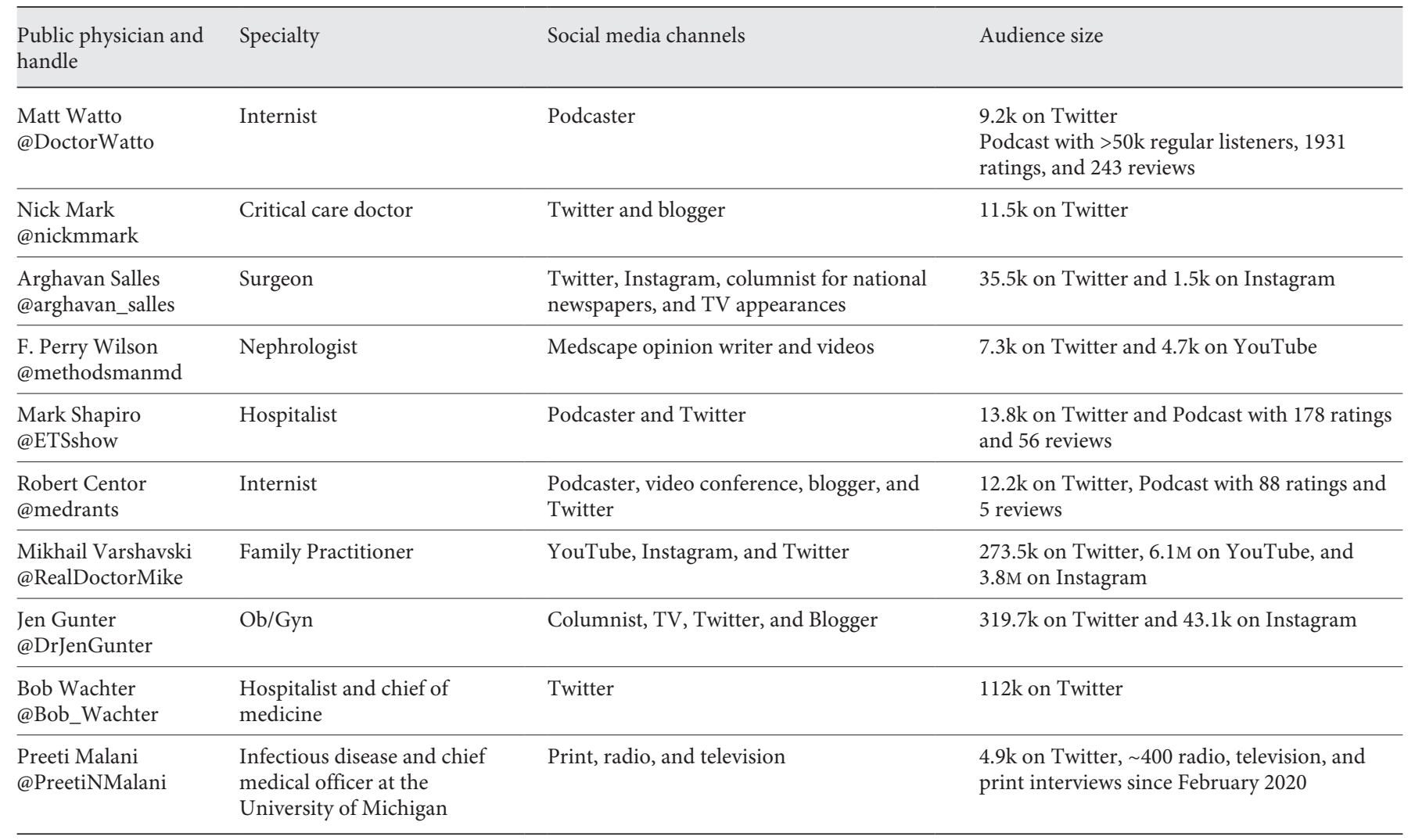

Despite these hazards, social media can be used to share quickly evolving information to those on the front line of care and to feedback information from the frontlines of care. Social media is a key tool that can shorten the time from publication to wide dissemination [3]. Social media can be used as a "just in time" means of information sharing, as shown by one group's rapid dissemination of an airway management infographic via Twitter and WeChat [11]. Social media also has the potential to be harnessed to support the public health response by communicating reasons for social distancing, providing reassurance when appropriate, and giving practical advice on living in this time of coronavirus [2].

In their review of coronavirus YouTube videos, D'Souza et al. [7] found that respected agencies such as the Centers for Disease Control and WHO were underrepresented, as were academic institutions. However, social media has allowed individuals to use their platforms to educate the public as well as their fellow healthcare providers. Prominent figures such as Drs. Esther Choo and Jeremy Faust have used their platforms to engage with the public during this time [3]. Physicians have historically been cautioned regarding their social media usage, but in this current era, they have the potential to use their platforms and expertise to shape the messaging around the coronavirus pandemic [12].

Indeed, there is a clear role for the "public physician" as defined by Dr. Bryan Vartabedian [13]. Dr. Vartabedian [13] identifies the public physician as someone who "sees public presence as part of their work," and "is intentional in the way he connects and creates." This physician is "outward-facing" and recognizes the value of visibility and engagement. Social media is an obvious tool for this engagement and can allow experts to openly and visibly debate topics, potentially identifying false information in real time [3]. Clinicians are often tempted to traffic solely in facts, but the public physician should be prepared to use crisis communication strategies to engage with the public and address, not just misinformation, but underlying sources of fear and anxiety [12].

For this perspective, we spoke to a convenience cohort of several prominent public physicians and asked them to 
discuss this role, what it means to them, how it has affected their lives, and how it has evolved during this time of the coronavirus pandemic [14]. The interviews were largely conducted over email. Additionally, both authors are public physicians and have first-hand experience with the change in perception and roles during the COVID-19 pandemic. Physicians that responded have various roles as public physicians (see Table 1).

\section{Platforms}

The physicians we interviewed had various platforms from traditional media including television and newspaper columns to pure social media on Twitter, Instagram, and YouTube. Most public physicians felt that their primary audience was other physicians, though they found COVID-19 broadened their appeal as more people sought information on the pandemic. Dr. Robert Wachter does weekly video conference grand rounds on Zoom and then moves the recordings to the University of California San Francisco YouTube channel where they average 40,000 views. The public physicians found that most of their content focused on the pandemic, as this was the primary subject on the minds of their audiences, especially at the beginning of the pandemic. Dr. Jen Gunter, who spends a lot of her public time confronting and disputing pseudoscience, felt that her role did not change much. She was very used to the attention and confrontation that comes from disputing conspiracies and false information. Her normal beat crosses the intersection of science and sex, so she is used to controversy and politics in her social media confrontations. And a lot of what came out of the COVID-19 pandemic felt familiar. Dr. Preeti Malani, chief medical officer of the University of Michigan, found her role as a public physician exploded with the pandemic. While she did occasional interviews prior to the pandemic, since February 2020, she has found herself constantly in front of a camera or microphone. She estimates she has done 400 interviews since the pandemic began and now is regularly recognized by strangers when she goes about her private life.

\section{Content}

Dr. Mike Varshavski's YouTube channel normally does a lot of entertainment, but during the peak of the COVID-19 pandemic, he redirected his videos to answer core and important questions people had regarding coro- navirus. Dr. Wilson similarly reprogrammed his channel to cover COVID-19. Dr. Salles had a similar focus on COVID-19 in March through May but noted a change in interest in June with the emergence of Black Lives Matter and interest in social justice concerns following the murder of George Floyd [15].

In addition to changes in the content that public physicians discussed there was also a change in the way some of these physicians approached the content they produced. Previously, Dr. Mark focused on innovations in critical care medicine. But with the increased interest in critical care and the influx of less experienced people needing to expand their knowledge of acute respiratory distress syndrome and ventilatory management, he shifted from cutting-edge innovation to emphasizing clinical excellence through one-page descriptions of various intensive care unit therapeutics and procedures on his blog (https://www.onepagericu.com). Dr. Watto's podcast (co-author Dr. Williams is also a host) The Curbsiders, focused a lot of coverage on the epidemic and increased the frequency of their periodic "journal club" episodes to cover new therapeutics and emerging evidence on the disease. Before the pandemic, Dr. Wachter focused on hospital medicine, quality, safety, and innovations through the use of electronic medical records. However, in March, he embraced the role of educator on COVID-19 and has been entirely focused on the COVID-19 pandemic since then.

While most public physicians reported that their audience not only grew during the pandemic but also became more diverse as more people became interested in the pandemic, Dr. Shapiro reported his audience sharpened and narrowed to be more healthcare oriented. Dr. Shapiro's podcast, Explore the Space, predominantly interviews medical professionals, but also includes athletes, politicians, and academics. Even his medical interviews skew toward a more general audience, with discussions about coffee, fitness, leadership, and social justice. During the pandemic, Shapiro's guests, and the focus of his interviews, have sharpened to focus more on the community of physicians and their welfare. As a result, his audience has shifted in that direction while the content remains accessible to a broad audience.

Dr. Salles noted that she found herself doing yoga as a form of self-care during the pandemic. She began tweeting images of her yoga, which became popular. She started tweeting these with the hashtag \#SocialDistancingFitnessChallenge, which eventually became a collective movement of people exercising while maintaining safe public health standards. Social media became a way for 
people to come together metaphorically while they stayed apart physically. Dr. Salles also notes that her typical "lane" of highlighting women in medicine has taken a back seat during the epidemic and racial justice movements of the summer.

Dr. Wilson promotes medical education on YouTube. He performs critical analysis of clinical studies, and one of his earlyvideos (https://www.youtube.com/watch?v=6$184 \mathrm{Zk} 7 \mathrm{yVU}$ ) during the pandemic looked at the data on lopinavir and hydroxychloroquine. It was the latter that got him in trouble. Some pro-hydroxychloroquine groups saw the video and its lukewarm conclusions ("some biologic plausibility, no compelling data yet") and attempted to use a YouTube rule designed to curb misinformation regarding the pandemic to get this video removed. Ironically, this rule was designed to limit videos that promote unproven treatments, so a pro-hydroxychloroquine group complained that Wilson's video was promoting the unproven treatment of hydroxychloroquine in order to muzzle his weakly negative review of hydroxychloroquine. In addition to having the video taken down, Wilson was given one "strike." If a YouTube creator receives 3 strikes, they lose their account, their videos, and their audience. Wilson writes, "Fortunately, I posted about the experience on Twitter and got a lot of support from some very pro-science YouTubers who were able to lobby to get the video put back up (and the strike removed). So it did end up being a victory for science, but it helps to illustrate how rough it is out there, especially for people who do not have the supportive colleagues that I do."

\section{Politics}

The passionate response to a mildly negative review of hydroxychloroquine is a result of politics being injected into the COVID-19 infodemic. We asked if the public physicians had noted an increase in Politics in their feed or in their audience. While Drs. Watto, Wilson, Centor, Malani, and Mark specifically avoided politics in their roles as public physicians, Wilson specifically noted increased politics in his audience. He has been accused of being a member of the "radical left" or "just a democrat" or "the deep state." Being a leader in the public discussion regarding abortion rights, Dr. Gunter has always had a lot of politics in her content and the pandemic did not meaningfully change that. Dr. Varshavski elegantly described his experience with the politicization of medicine, "[The] Audience is without a doubt becoming more political. Medical discussions unfortunately are becoming more

Public Physicians in the COVID-19

Pandemic politicized. I tend to point out where political polarization is driving information regarding the pandemic, but I try not to get into direct political conversations. I have never called out misinformation by politicians prior to this pandemic." And, Wachter says that if you are really covering and digging in on COVID-19, it invariably results in a discussion of policy and that is political by its nature. He tries to remain neutral, but the facts often align up against one side of the political spectrum.

\section{Misinformation}

The public physicians feel that a lot of their mission is to specifically call out and correct misinformation they see. Dr. Mark recounted a story he was involved in. Dr. Steven Salzberg [16], a Johns Hopkins University professor and biomedical engineer, wrote an editorial in Forbes advocating skipping phase 3 trials to speed inoculation. This was met with a wave of pushback including thousands of tweets and an editorial in The New York Times [17, 18]. Dr. Mark was part of this wave pushing back on the initial story, and a few days later, Dr. Salzberg [19] reversed himself in an article explaining what he got wrong and how he misunderstood vaccine trials.

Dr. Malani feels the same obligation to correct mistakes that most of the public physicians feel. She says that she is seeing a lot of nonepidemiologists drawing conclusions with neither formal training nor complete data. She points out that these are intelligent people, often with deep knowledge about statistics but without formal epidemiologic training, so they can draw erroneous or incomplete conclusions.

\section{Discussion}

The coronavirus pandemic has occurred during an unprecedented age of simultaneous atomization and connectivity. The accompanying infodemic has posed significant challenges in terms of controlling misinformation and prioritizing the sharing of new data. Physicians have historically been cautioned to maintain strict boundaries when engaging in the social media space, keeping a clear line drawn between professional and personal identity [20]. But a new paradigm is emerging, a paradigm that is probably better suited to addressing the present infodemic - that of the public physician.

Vartabedian defines the public physician: someone who sees the public presence as part of their work, who is 
outward-facing, and who recognizes that the benefits of public engagement outweigh the risks [13]. Each of these elements is worth examining. The physicians we interviewed clearly view part of their role as being a public presence. Dr. Gunter has created a public presence to debunk myths. Similarly, Dr. Mark has used his growing Twitter platform with the intention to correct or preempt misinformation as well as spread best and evidence-based medicine in critical care. Dr. Salles has leveraged her social media presence to address social justice issues, such as organizing the \#ShareTheMicNowMed campaign to amplify the voices of Black women in medicine.

Physicians actively engaged in social media are by definition "outward-facing," but the doctors we have spoken to exemplify this practice. Dr. Wachter has had over 60 million views of his tweets since the coronavirus pandemic began. Dr. Varshavski counts millions of subscribers across multiple platforms, including YouTube, Instagram, and Facebook. Many of the physicians we talked to reported that the number of people following them swelled with the onset of COVID-19. But more importantly, many of them also felt that their followers were more engaged. Dr. Wachter states that there is "far more interest by lay public in this than anything I've ever seen. [They are] sophisticated, they keep up... [the] lay audience asks sophisticated questions, follows the literature." $\mathrm{He}$ also notes that the overwhelming tone of engagement is respectful.

This respectful tone is not universal, however, and there are indeed risks in being publicly engaged. When the University of Michigan went forward with having students on campus in the fall of 2020, Dr. Malani's Facebook profile was bombarded with hurtful and aggressive messages from angry parents. This forced her to pull her public Facebook profile to protect her mental health.

Most of our respondents stated that their audiences grew, and their focus narrowed in response to the coronavirus pandemic. But each of them was uniquely positioned to address the accompanying infodemic by embracing their role as a public physician. The social media space allows physicians to provide high-quality information, to fact-check and repudiate misinformation, and ultimately to shape the narrative around disease, and potentially modify its course. The COVID-19 pandemic highlights these opportunities for the public physician to leverage their outward-facing role to significantly impact public health in a meaningful and positive way.

\section{Acknowledgements}

The authors would like to acknowledge the public physicians we interviewed for this paper: Matthew Watto, Nick Mark, Arghavan Salles, F. Perry Wilson, Mark Shapiro, Robert Centor, Mikhail Varshavski, Jen Gunter, Bob Wachter, and Preeti Malani.

\section{Statement of Ethics}

This paper is exempt from Ethical Committee approval. All participants were told the nature of the paper prior to the interview. There was no promise of reimbursement for anyone's participation.

\section{Conflict of Interest Statement}

Both authors are public physicians. Otherwise, the authors have no conflicts of interest to declare.

\section{Funding Sources}

No funding was used for this paper.

\section{Author Contributions}

J.T. conceived of the paper and outlined the scope. P.W. wrote a partial early draft and developed the outline. Both authors reached out to their contacts to develop the list of public physicians to interview. J.T. wrote an early draft of the interview questions but both authors jointly finalized the questions. Both authors worked on the final version of the manuscript. J.T. was chiefly responsible for responding to the editors' questions and suggestions.

\section{References}

1 Tangcharoensathien V, Calleja N, Nguyen T, Purnat T, D'Agostino M, Garcia-Saiso S, et al. Framework for managing the COVID-19 infodemic: methods and results of an online, Crowdsourced WHO Technical consultation. J Med Internet Res. 2020 Jun;22(6):e19659.

2 Depoux A, Martin S, Karafillakis E, Preet R, Wilder-Smith A, Larson H. The pandemic of social media panic travels faster than the COVID-19 outbreak. J Travel Med. 2020 May; 27(3):taaa031.
3 Gottlieb M, Dyer S. Information and disinformation: social media in the COVID-19 crisis. Acad Emerg Med. 2020 Jul;27(7):640-1.

4 Andrews TM. Why dangerous conspiracy theories about the virus spread so fast: and how they can be stopped. 2020 May

5 Cerulus L. How anti-5G anger sparked a wave of arson attacks. 2020. 
6 Basch CH, Hillyer GC, Jaime C. COVID-19 on TikTok: harnessing an emerging social media platform to convey important public health messages. Int J Adolesc Med Health. 2020 Aug.

7 D'Souza RS, D'Souza S, Strand N, Anderson A, Vogt MNP, Olatoye O. YouTube as a source of medical information on the novel coronavirus 2019 disease (COVID-19) pandemic. Glob Public Health. 2020 Jul;15(7): 935-42.

8 Li HO-Y, Bailey A, Huynh D, Chan J. YouTube as a source of information on COVID-19: a pandemic of misinformation? BMJ Glob Health. 2020 May;5(5):e002604.

9 Allington D, Duffy B, Wessely S, Dhavan N, Rubin J. Health-protective behaviour, social media usage and conspiracy belief during the COVID-19 public health emergency. Psychol Med. 2020 Jun:1-7.

10 Bozdag E. Bias in algorithmic filtering and personalization. Ethics Inf Technol. 2013 Sep; 15(3):209-27.
11 Chan AKM, Nickson CP, Rudolph JW, Lee A, Joynt GM. Social media for rapid knowledge dissemination: early experience from the COVID-19 pandemic. Anaesthesia. 2020 Dec; 75(12):1579-82.

12 Malecki K, Keating JA, Safdar N. Crisis communication and public perception of $\mathrm{CO}$ VID-19 risk in the era of social media. Clin Infect Dis. 2020 Jun.

13 Vartabedian B. The public physician defined [Internet]. 33 charts. 2020 Jan [cited 2020 Sep 14]. Available from: https://33charts.com/ public-physician-defined/.

14 Rossi PH, Wright JD, Anderson AB. Handbook of survey research. Academic Press; 2013.

15 Hill E, Tiefenthäler A, Triebert C, Jordan D, Willis H, Stein R. How George Floyd was killed in police custody. 2020 Jun [cited 2020 Sep 13]. Available from: https://www.nytimes.com/2020/05/31/us/george-floyd-investigation.html.
16 Salzberg S. We should consider starting Covid-19 vaccinations now. 2020 Aug [cited 2020 Sep 14]. Available from: https://www. forbes.com/sites/stevensalzberg/2020/08/02/ start-vaccinating-now/.

17 Dean N. A coronavirus vaccine is coming Just don't call it "Warp Speed". 2020 Aug [cited 2020 Sep 14]. Available from: https://www. nytimes.com/2020/08/03/opinion/sunday/ coronavirus-vaccine-efficacy-trials.html.

18 Feuerstein A, Robbins R, Garde D. The story of a scientist's mea culpa on Covid-19 vaccines [Internet]. 2020 Aug [cited 2020 Sep 14]. Available from: https://www.statnews.com/ 2020/08/07/the-story-of-a-scientists-meaculpa-on-covid-19-vaccines-and-a-roughweek-on-twitter/.

19 Salzberg S. I was wrong: we can't skip phase 3 vaccine trials. 2020 Aug [cited 2020 Sep 14]. Available from: https://www.forbes.com/sites/ stevensalzberg/2020/08/03/i-was-wrong-wecant-skip-phase-3-vaccine-trials/.

20 DeCamp M, Koenig TW, Chisolm MS. Social media and physicians' online identity crisis. JAMA. 2013 Aug;310(6):581-2. 